\title{
Hyperemesis gravidarum in the primary care setting: cross-sectional study of GPs
}

\author{
Melanie Nana', Holly Morgan², Haroon Ahmed ${ }^{3}$, Catherine Williamson4* \\ 'Department of Obstetric Medicine, St Thomas' Hospital, London, UK; ${ }^{2}$ Department \\ of Cardiology, King's College London, London, UK; ${ }^{3}$ Division of Population Medicine, \\ Cardiff University School of Medicine, Cardiff, UK; ${ }^{4}$ Department of Life Course \\ Sciences, King's College London, London, UK
}

\begin{abstract}
Background: Hyperemesis gravidarum (HG), if untreated, can lead to malnutrition, dehydration, and Wernicke's encephalopathy. Foetal complications include low birth weight and neurodevelopmental delay. Recent evidence supports increased rates of termination of pregnancy and suicidal ideation. Drivers included difficulty in accessing medications, which thus contributed to poor perception of care.
\end{abstract}

Aim: To identify factors that may influence prescribers' confidence and knowledge regarding pharmacological therapy for HG.

Design \& setting: Cross-sectional study of qualified GPs and GP trainees in Wales.

Method: Distribution of a 22-item online survey. Statistical analysis was carried out using SPSS.

Results: In total, 241 responses were received, with 216 included in the analysis (59\% qualified GPs, $41 \%$ GP trainees). In total, $93 \%$ of responders correctly identified cyclizine as being safe in pregnancy, but no other drug recommended in the Royal College of Obstetrics and Gynaecology guidance was considered safe by more than $58 \%$. Those reporting higher confidence levels in managing HG were more likely to correctly report guideline-recommended drugs as safe in pregnancy $(P=0.04)$. Additional qualifications related to obstetrics and gynaecology $(O \& G)$ and/or prior clinical experience increased confidence levels $(P=0.0001$ and $P=0.0002$, respectively). Only $19 \%$ of participants routinely screened for signs of mental health complications, and prior experience or education did not increase likelihood of this happening. The majority of participants (87\%) would like additional education and/or access to evidence-based resources.

Conclusion: This study demonstrates a demand for improved dissemination of evidence-based education on HG to support those working in primary care. The extent to which HG is covered in preexisting educational programmes should also be revisited.

*For correspondence: catherine. williamson@kcl.ac.uk

Received: 03 July 2021

Accepted: 02 September 2021

Published: 08 December 2021

(C)This article is Open Access: CC BY license (https://creativecommons.org/licenses/by/4.0/)

Author Keywords: hyperemesis gravidarum, education, pregnancy, antiemetics, primary health care, general practice

Copyright (C) 2021, The Authors; DOI:10.3399/BJGPO.2021.0119

\section{How this fits in}

To the authors' knowledge this is the first study to explore the factors that influence the management of those caring for women with HG in primary care. The study demonstrates the need to better support clinicians by providing access to education and comprehensive guidance. The extent to which HG is covered in pre-existing educational programmes should also be revisited. Work is now ongoing to develop e-learning material and to update and publicise guidance. 


\section{Introduction}

HG describes nausea and vomiting in pregnancy excessive enough to result in dehydration and weight loss. ${ }^{1}$ It complicates between $0.3 \%-3.6 \%$ of pregnancies, which equates to between $1900-23000$ affected women in the UK per year. ${ }^{1-3}$

Presentation includes severe intractable vomiting, often associated with $>5 \%$ weight loss, dehydration, and electrolyte imbalance, with symptoms typically starting between the seventh and ninth week of pregnancy. ${ }^{3,4}$ Untreated, it may result in complications secondary to malnutrition and dehydration. Maternal complications include electrolyte disturbance (15\%-28\%), Wernicke's encephalopathy (secondary to thiamine deficiency; $<1 \%$ ), and susceptibility to thrombus. ${ }^{5,6}$ Mental health complications include increased rates of anxiety $(46 \%)$, depression (48\%), and suicidal ideation (7\%). ${ }^{7-13}$ Effects on the foetus include a four-fold increased risk of low birthweight and preterm birth, and three-fold increased odds of neurodevelopmental delay. ${ }^{14,15}$

Initial management is typically carried out in primary care comprising use of first line anti-emetics (antihistamines and phenothiazines). ${ }^{16}$ Practitioners should assess a woman's mental health status and refer for psychosocial support if necessary. ${ }^{16}$ Timely community-based treatment, including prompt pharmacological therapy where required, should be offered to avoid complications. ${ }^{17,18}$ Inpatient management should be considered in women who, despite treatment with oral anti-emetics, have persistent vomiting, clinical evidence of dehydration, weight loss of $>5 \%$ of their body weight, or a confirmed or suspected comorbidity. ${ }^{16}$

In a recent survey of $>5000$ women with $\mathrm{HG}, 40 \%$ perceived their experience in primary care to be poor or extremely poor in terms of HG management. ${ }^{13}$ These women were more likely to terminate a wanted pregnancy as a consequence of $\mathrm{HG}$ or experience suicidal ideation. They were more likely to have struggled accessing medication, with $48 \%$ of those taking medications having to actively request it as opposed to being offered it. Qualitative analysis confirmed difficulty accessing appropriate treatment with a negative impact on the ability of affected women to look after family and earn a living. The study also revealed marked variations in the attitude of healthcare professionals towards women with HG.

A number of factors may contribute to a delay in timely prescription of anti-emetics in pregnancy. The 1960s thalidomide disaster rendered all medications used in pregnancy suspect of teratogenicity. ${ }^{19}$ As such, practitioners exercise significant caution prescribing in pregnancy. However, a Cochrane review and other systematic reviews and meta-analyses have now reported on the safety and efficacy of many anti-emetics in pregnancy with no increased risk of teratogenesis or other adverse outcomes, and so a risk-benefit decision should be made between prescribing such medications and the risks of untreated HG. ${ }^{20,21}$

GPs see a large number of patients every day, making decisions on a wide range of medical problems. While it is unreasonable to expect detailed sub-specialty knowledge, it is imporant that GPs are provided with evidence-based information regarding management of such patients, and that opportunities are available to those wishing to develop knowledge in this area so that patients can be supported in gaining timely access to treatment. Available guidance includes The Royal College of Obstetricians and Gynaecologists (RCOG) Green-top guideline and the National Institute for Health and Care Excellence Clinical Knowledge Summary. ${ }^{16,22}$

This study aimed to explore the confidence of GPs in managing HG patients in Wales and their knowledge surrounding pharmacological therapy. It aimed to identify factors that may influence these and explore methods by which GPs could be supported in terms of education, resources, and continued professional development.

\section{Method}

This cross-sectional study utilised a 22-item online survey developed using the online platform surveymonkey.com. The survey was piloted by the Pregnancy Sickness Support charity chairman and two GPs based in Wales (one trainee and one qualified GP, both with an interest in medical education) with feedback incorporated. Included questions were either multiple choice or open comment (Supplementary Table S1).

An invitation to complete the survey was sent out to qualified GPs and GP trainees, between 19 January and 5 March 2020, via a number of avenues. Emails were sent to all postgraduate centres 
and the head of the School of General Practice at Health Education and Improvement Wales to enable dissemination to GP trainees. The link was also sent to regional primary care representatives for dissemination to qualified GPs, and was posted on social media.

The data requested included demographic information; prior experience in O\&G; previous education relating to $\mathrm{HG}$; access to and attendance at continued professional development education opportunities; confidence managing patients with $\mathrm{HG}$; practitioner knowledge regarding pharmacotherapy; services available to support the management of such patients; and data regarding whether further education opportunities would be valuable and in what form. All data were collected anonymously and voluntarily. All qualified GPs and GP trainees working in Wales were eligible to participate. Participants required access to the internet. Other allied healthcare professional and students were excluded.

It was not compulsory for participants to answer every question, thus the total response number for each question varies. Mean confidence scores were calculated by awarding 1-4 points depending on answer ( $1=$ not at all confident, 2 = not so confident, 3 = somewhat confident, 4 = very confident). Data are presented as percentages and raw numbers. For confidence scores, means have been used rather than medians to highlight differences between groups. Statistical analysis was carried out using SPSS (software version 11.0, IBM); Mann-Whitney $U$ and 2 tests were used for non-parametric data, and ANOVA for multiple groups. A value of $P<0.05$ was considered statistically significant.

\section{Results}

\section{Demographics}

A total of 241 responses were received. Of these, 13 were largely incomplete and 12 were filled in by other allied healthcare professionals. It was felt that, because the overall number of responses from allied healthcare professionals was small and there was not representation from more than three members of one allied healthcare group, these responses should be removed. Of the remaining 216 responses, $59 \%$ ( $n=128 / 216$ ) were completed by fully qualified GPs and $41 \%$ ( $n=88 / 216)$ by GP trainees. In terms of geographical location, $26 \%(n=57 / 216)$ of participants reported being from rural practices, $39 \%$ ( $n=85 / 216)$ suburban, and 34\% $(n=74 / 216)$ from urban practices (percentages do not total 100 due to rounding; Figure 1 and Supplementary Table S2).

\section{Experience and education}

In total $69 \%$ ( $n=150 / 216$ ) of responders reported having at least one additional postgraduate qualification or prior clinical experience related to $O \& G$. The nature of the qualification or experience is illustrated in Supplementary Figure S1. 38\% $(n=82 / 213)$ of participants reported having received previous teaching focused on HG. Open box comments revealed that this had taken place primarily in medical school or as part of departmental teaching on O\&G placements (Supplementary Table S2). Participants reported using a variety of resources to access further information regarding HG (Figure 2). 


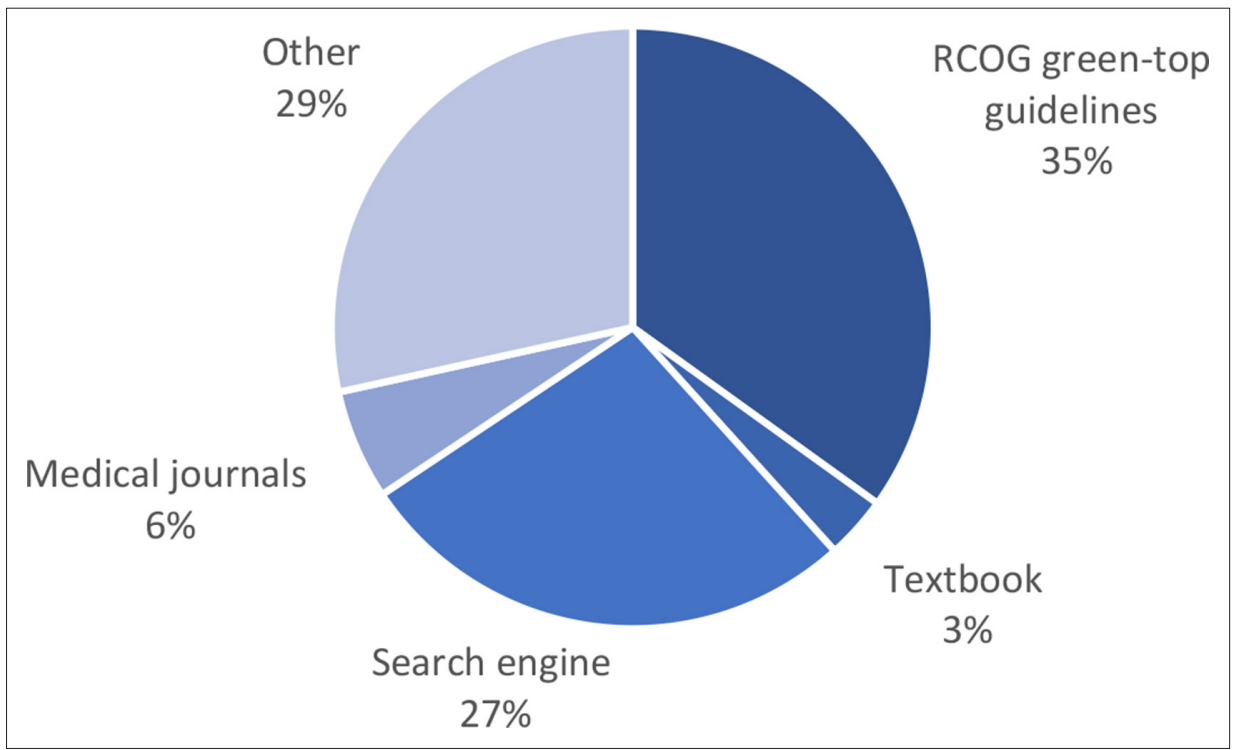

Figure 2 Breakdown of where participant would access further information on HG. 'Other' included the British Medical Journal resources, the British National Formulary, GP notebook, National Institute for Health and Care Excellence resources, patient information websites, and the website of a widely used GP educational resource (the 'Red Whale' website).

Regarding access to continued professional development (CPD), 92\% ( $n=198 / 216$ ) of participants reported that they attended or had access to community or GP teaching. $23 \%(n=50 / 213)$ routinely attend regional or national conferences, including the 'Hot Topics GP update course' and Royal College of General Practitioners conferences (Supplementary Table S2).

Qualified GPs were more likely to attend regional or national conferences than GP trainees $(P=$ $0.01)$, and geography did not affect this outcome. There was no association between grade of training or geography and any other education outcome (Supplementary Table S2).

\section{Confidence}

Participants were asked how confident they felt managing patients with HG (Figure 3).

The mean confidence scores for qualified GPs (3.0/4) were statistically significantly higher than the scores of GP trainees (2.7/4), $(P=0.002)$. Those who had an additional qualification or prior clinical experience related to $O \& G$ and those who had received previous teaching on $H G$ were also significantly more confident in managing HG, $(P=0.0001$ and $P=0.0002$, respectively) (Table 1).

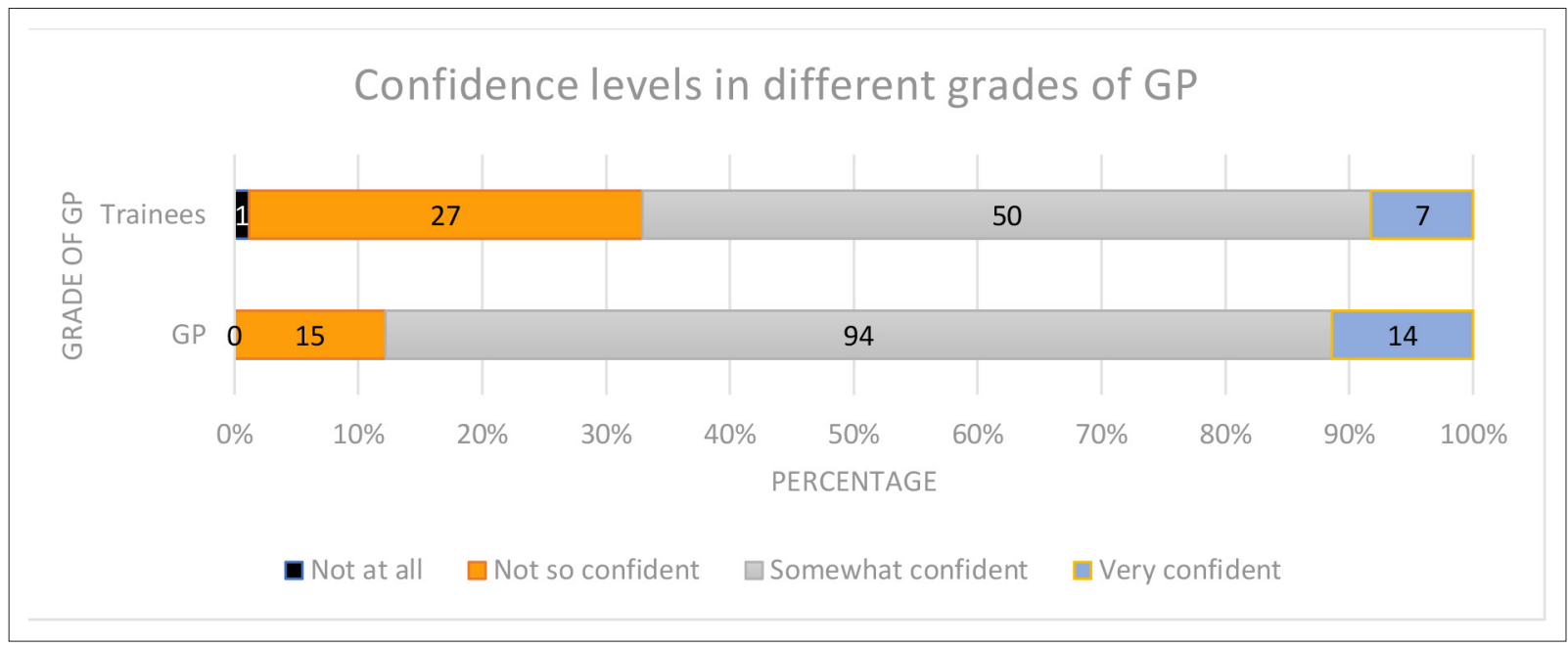

Figure 3 Participants confidence levels with regards to managing women with HG 
Table 1 Relationship between additional qualifications or training and confidence levels and likelihood of screening for mental health consequences in $\mathrm{HG}$.

\begin{tabular}{lcc}
\hline & $\begin{array}{c}\text { Confidence in } \\
\text { managing HG } \\
\text { (score/4) }\end{array}$ & $\begin{array}{c}\text { Routinely screen } \\
\text { for mental health } \\
\text { problems }\end{array}$ \\
\hline $\begin{array}{l}\text { Additional qualifications or prior clinical experience } \\
\text { related to O\&G }\end{array}$ \\
\hline Yes & 3.0 & $19 \%(27 / 145)$ \\
\hline No & 2.6 & $19 \%(12 / 64)$ \\
\hline$P$ value & $0.0001^{\text {a }}$ & 1.0 \\
\hline Attendance or access to community/ GP teaching \\
\hline Yes & 2.9 & $18 \%(35 / 192)$ \\
\hline No & 3.1 & $24 \%(4 / 17)$ \\
\hline$P$ value & 0.21 & 0.59 \\
\hline
\end{tabular}

Routine attendance at regional or national conferences

\begin{tabular}{lcc}
\hline Yes & 3.0 & $22 \%(11 / 49)$ \\
\hline No & 2.9 & $18 \%(28 / 160)$ \\
\hline$P$ value & 0.35 & 0.44
\end{tabular}

Previous teaching on $\mathrm{HG}$

\begin{tabular}{lcc}
\hline Yes & 3.1 & $17 \%(13 / 78)$ \\
\hline No & 2.8 & $20 \%(26 / 131)$ \\
\hline$P$ value & $0.0002^{\mathrm{a}}$ & 0.31 \\
\hline
\end{tabular}

a Statistically significant.

in pregnancy, with $52.2 \%$ feeling comfortable prescribing it in primary care. (Supplementary Table S3).

In total, $47 \%$ of participants believed that thiamine, recommended to prevent Wernicke's encephalopathy, is safe throughout pregnancy; $19 \%$ believed it should not be prescribed in pregnancy; and $39 \%$ believed it should be reserved for secondary care prescription only (Supplementary Table S3).

Responders with higher confidence levels in managing HG were significantly more likely to report guideline-recommended drugs being safe in pregnancy $(P=0.04)$ and significantly less likely to report that guideline-recommended medications should not be prescribed in pregnancy $(P=0.04)$. There were trends towards increased numbers of participants reporting guideline-recommended medications being safe in pregnancy in those with additional qualifications or clinical experience, and in those who had previous teaching on HG (Table 2).

Overall, $19 \%(n=39 / 207)$ of participants stated that they routinely screen women with HG for signs of mental health problems. The likelihood of performing screening was not affected by having obtained additional education (Table 1). Only $7 \%(n=12 / 164)$ of participants had access to mental health counselling (four working in urban practices, five in suburban, and three in rural practices).

\section{Additional education}

In total, $87 \%$ ( $n=141 / 163$ ) of participants reported that they would like to receive additional education or have access to additional resources. In terms of the educational material that they would like to receive (participants were able to 'tick all that apply'), the most common responses included online e-learning (117 participants), online guidelines (108 participants), and teaching integrated into the GP training programme (87 participants). 
Table 2 Participant knowledge and comfort in prescribing first line anti-emetics and all drugs recommended in guidelines

\begin{tabular}{|c|c|c|c|c|}
\hline & \multicolumn{3}{|c|}{ Safety of medications in pregnancy } & \multirow{2}{*}{$\begin{array}{l}\text { Comfort of physician in prescribing } \\
\text { in primary care }\end{array}$} \\
\hline & $\begin{array}{l}\text { Participants reporting first } \\
\text { line anti-emetics being } \\
\text { safe throughout } \\
\text { pregnancy, } \%\end{array}$ & $\begin{array}{l}\text { Participants reporting all } \\
\text { guideline-recommended } \\
\text { drugs being safe in } \\
\text { pregnancy, } \%\end{array}$ & $\begin{array}{l}\text { Participants reporting first } \\
\text { line anti-emetics not being } \\
\text { safe in pregnancy, } \%\end{array}$ & \\
\hline \multicolumn{5}{|l|}{ Confidence levels } \\
\hline $\begin{array}{l}\text { Not at all/not so } \\
\text { confident }\end{array}$ & $27 \%$ & $28 \%$ & $7 \%$ & $30 \%$ \\
\hline $\begin{array}{l}\text { Somewhat } \\
\text { confident }\end{array}$ & $52 \%$ & $50 \%$ & $5 \%$ & $17 \%$ \\
\hline Very confident & $55 \%$ & $57 \%$ & $5 \%$ & $17 \%$ \\
\hline$P$ value & 0.09 & $0.04^{a}$ & 0.49 & $0.04^{\mathrm{a}}$ \\
\hline \multicolumn{5}{|c|}{ Additional qualifications/additional clinical experience } \\
\hline Yes & $52 \%$ & $50 \%$ & $5 \%$ & $19 \%$ \\
\hline No & $37 \%$ & $37 \%$ & $7 \%$ & $21 \%$ \\
\hline$P$ value & 0.24 & 0.11 & 0.23 & 0.38 \\
\hline \multicolumn{5}{|c|}{ Previous teaching on hyperemesis gravidarum (HG) } \\
\hline HG teaching & $52 \%$ & $49 \%$ & $5 \%$ & $16 \%$ \\
\hline No HG teaching & $43 \%$ & $43 \%$ & $6 \%$ & $21 \%$ \\
\hline$P$ value & 0.34 & 0.29 & 0.27 & 0.18 \\
\hline
\end{tabular}

a Statistically significant. HG = hyperemesis gravidarum.

\section{Discussion}

\section{Summary}

This study collated responses from 216 GPs of varying grade and geographical distribution across Wales, consistent with response numbers from similar studies. ${ }^{23,24}$ In total, 69\% of participants had at least one postgraduate qualification or prior clinical experience relating to O\&G. Despite this, only $38 \%$ reported receiving previous teaching focused on HG. Grade of training and geography did not affect likelihood of having additional experience, teaching, or access to CPD.

The majority of participants (93\%) felt comfortable prescribing cyclizine in pregnancy. The proportion of responders that felt comfortable prescribing the other three first line recommended anti-emetics (prochlorperazine, promethazine, and chlorpromazine) was 57\%, 46\%, and 15\%, respectively. Clinical evidence of dehydration, inability to tolerate oral anti-emetics, and ketonuria represented the most common reasons for a participant to decide to admit a patient.

Those who reported increased levels of confidence in managing HG were significantly more likely to report all guideline-recommended drugs being safe in pregnancy and significantly less likely to report that guideline-recommended medications should not be prescribed in pregnancy (Table 2). Prior additional qualifications or clinical experience related to $O \& G$ and previous teaching on $H G$ were identified as factors that increased confidence levels. These factors additionally supported trends towards participants being more likely to report guideline-recommended medications being safe in pregnancy (Table 2).

Only $19 \%$ routinely screened women with HG for signs of mental health problems, with no increased likelihood of screening occurring in those with additional qualifications, prior clinical experience, or previous teaching on HG (Table 1). Only 7\% of participants reported having access to mental health counselling.

There was a clear demand for additional education and access to additional resources. The majority of participants expressed a preference for learning materials in the form of online e-learning, online guidelines, and teaching integrated into the GP training programme. 


\section{Strengths and limitations}

To the authors' knowledge, this is the first study to explore the factors that influence the management of those caring for women with HG in primary care. Online distribution of the survey, via a number of avenues, facilitated the acquisition of responses from a number of GPs, with representation from a range of training grades and geography. As with all survey-based studies, this study is limited by the risk of responder bias and reliance on participants fully understanding each question, and thus providing 'conscientious responses'. Responders were not obliged to complete each question; a degree of 'survey fatigue' was observed, with a degree of participant drop out throughout the survey. The survey nature of the work does not allow the authors to further explore reasons for increased completion of certain questions over others. This study focused on GPs, but the authors recognise the importance of input from the multidisciplinary team in the management of women with HG. As such, it will be important for future work to also focus on the knowledge and confidence in managing HG of the wider multidisciplinary team.

\section{Comparison with existing literature}

Extensive literature exists describing the burden of HG on patient's physical and mental health., 5,9,10 In addition, HG is the most common reason for hospitalisation during pregnancy, the subsequent financial burden on the health service being estimated at approximately 36.5 million pounds per year. ${ }^{25-28}$

A large population-based cohort study identified 37856 women who experienced nausea and vomiting in pregnancy (NVP) or HG. Of these, 6390 had a hospital admission prior to 20 weeks and 2425 after 20 weeks' gestation. ${ }^{29}$ Only $38 \%$ and $23 \%$, respectively, had evidence of primary care prescription of anti-emetics before admission. Challenges in accessing pharmacotherapy for HG in primary care are well documented, with $48 \%$ of women taking medications in a recent study having had to actively request it, despite it being acknowledged that early treatment may prevent admission. ${ }^{11,13,30,31}$ This study's findings propose a possible rationale for those findings, as it has demonstrated lack of confidence in prescribing first line anti-emetics in pregnancy. National guidelines for the managements of NVP and HG were published in 2016, providing recommendations on the management of such women; despite this, only $39 \%$ of participants in this study felt comfortable prescribing first line recommended treatments, and only $35 \%$ of participants refer to these guidelines when seeking further information regarding HG. ${ }^{16}$

This study reported that $59 \%$ of participants consider ondansetron as being safe in pregnancy, with a $52 \%$ feeling comfortable prescribing it in primary care. A controversial statement issued by the European Medicines Agency in August 2019 recommended that ondansetron should not be prescribed in the first trimester of pregnancy due to concerns regarding the risk of orofacial malformations. ${ }^{32}$ The UK teratology information service have since issued an official response statement summarising the increased risk of orofacial clefts equates to an additional three cases per 10000 pregnancies exposed to ondansetron..$^{33}$ As such, ondansetron should be reserved as a second line agent but not exclusively avoided in the first trimester of pregnancy; this statement is supported by the RCOG guidelines. ${ }^{16}$ In many cases, the benefit of ondansetron will outweigh the risks, and it is therefore reassuring that over half of GPs in this study were comfortable prescribing it in primary care.

Only $19 \%$ of participants were screening for mental health problems. Previously published literature supports a lack of attention being paid towards the detrimental mental health consequences of HG. Previous studies exploring patient experience describe feelings of not being believed and stigma being displayed towards those with HG.9.11,34 In this study, additional qualifications or prior clinical experience related to $O \& G$, nor previous teaching on $H G$, increased the likelihood of a participant screening for mental health problems, suggesting that current education surrounding HG does not adequately cover the psychiatric burden of the condition.

In total, 185 participants selected ketonuria as an indication for deciding to admit a patient with HG to hospital. While the presence of ketones reflects starvation and is therefore a possible surrogate marker of severity in $\mathrm{HG}$, it is increasingly being recognised that its use as a 'gatekeeper' for admission is flawed since this is not the only manifestation of severity of HG and does not reflect degree of dehydration. ${ }^{35}$ As such, use of ketone measurement will be excluded in the next iteration of the RCOG guidance. 
Table 3 List of recommended resources for healthcare professionals.

\begin{tabular}{|c|c|}
\hline \multicolumn{2}{|l|}{ Recommended resources } \\
\hline $\mathrm{RCOG}$ & $\begin{array}{l}\text { The Management of Nausea and Vomiting of Pregnancy and } \\
\text { Hyperemesis Gravidarum- Green-top Guideline }\end{array}$ \\
\hline $\begin{array}{l}\text { National Institute for Health and Care } \\
\text { Excellence }\end{array}$ & Nausea/vomiting in pregnancy- Clinical Knowledge Summary \\
\hline UK Teratology Information Service & Treatment of Nausea and Vomiting in Pregnancy \\
\hline UpToDate & Nausea and vomiting of pregnancy: Treatment and outcomes \\
\hline Red Whale & $\begin{array}{l}\text { https://www.gp-update.co.uk/Latest-Updates/Nausea-and-vomiting-in- } \\
\text { pregnancy }\end{array}$ \\
\hline Pregnancy Sickness Support charity & Section for Healthcare Professionals \\
\hline HER Foundation & Section for Healthcare Providers \\
\hline
\end{tabular}

\section{Implications for practice}

This study demonstrates the need to support those in primary care in looking after women with HG by providing access to education and comprehensive guidance. The small proportion of GPs having confidence in prescribing guideline-recommended treatments, as well as low numbers reporting referring to guidance when requiring further information on HG, suggests the guidance needs to be better publicised and more accessible. Recommended resources are outlined in Table 3.

Confidence, and thus appropriate selection of safe medications, was increased in those with previous postgraduate qualifications or clinical experience related to $O \& G$, and previous teaching on HG. Participants unanimously reported a hunger for additional education, suggesting online e-learning as preferred method of delivery which should prompt further work in developing such resources.

Only a proportion undertaking additional qualifications or with clinical experience related to O\&G had undertaken previous teaching on HG. In addition, previous education made no difference on likelihood of screening for mental health problems, suggesting that syllabus' and curriculums should be revisited to ensure that they adequately cover this profound disease.

Funding

This project is funded by the National Institute for Health Research (NIHR) Senior Investigator Award (NIHR200254). The views expressed are those of the authors and not necessarily those of the NIHR or the Department of Health and Social Care.

Ethical approval

All data were anonymous with no means of accessing identifiable information or linking any data. The study was discussed with the local Research and Ethics Committee and approved as exempt (HEIW REC).

\section{Provenance}

Freely submitted; externally peer reviewed.

\section{Acknowledgements}

The authors would like to acknowledge Caitlin Dean for piloting the survey and Evie Lambert, Emma Rengasamy, and Sacha Moore for helping distribute the survey. The authors are particularly grateful to those GPs who gave up their time to complete the survey.

\section{References}

1. Einarson TR, Piwko C, Koren G. Quantifying the global rates of nausea and vomiting of pregnancy: a meta analysis. J Popul Ther Clin Pharmacol 2013; 20(2): 171-183.

2. World Health Organisation. International classification of diseases-11 for mortality and morbidity statistics. 2018; https://icd.who.int/browse11/I-m/en (accessed 25 Oct 2021).

3. Gadsby R, Barnie-Adshead AM, Jagger C. A prospective study of nausea and vomiting during pregnancy. $\mathrm{Br} J \mathrm{Gen}$ Pract 1993; 43(371): 245-248. 
4. Verberg MFG, Gillott DJ, Al-Fardan N, Grudzinskas JG. Hyperemesis gravidarum, a literature review. Hum Reprod Update 2005; 11(5): 527-539. DOI: https://doi.org/10.1093/humupd/dmi021

5. Eliakim R, Abulafia O, Sherer DM. Hyperemesis gravidarum: a current review. Am J Perinatol 2000; 17(4): $207-218$. DOI: https://doi.org/10.1055/s-2000-9424

6. Sciarra JJ. Gynecology and obstetrics. Volumes 1-6. Hagerstown: Lippincott Williams \& Wilkins; 2004.

7. McCormack D, Scott-Heyes G, McCusker CG. The impact of hyperemesis gravidarum on maternal mental health and maternal-fetal attachment. J Psychosom Obstet Gynaecol 2011; 32(2): 79-87. DOI: https://doi.org/10.3109/ $0167482 X .2011 .560691$

8. Loveland Cook CA, Flick LH, Homan SM, et al. Posttraumatic stress disorder in pregnancy: prevalence, risk factors, and treatment. Obstet Gynecol 2004; 103(4): 710-717. DOI: https://doi.org/10.1097/01.AOG.0000119222.40241. $\mathrm{fb}$

9. Poursharif B, Korst LM, Fejzo MSet al. The psychosocial burden of hyperemesis gravidarum. J Perinatol 2008; 28(3): 176-181. DOI: https://doi.org/10.1038/sj.jp.7211906

10. King NMA, Chambers J, O'Donnell K, et al. Anxiety, depression and saliva cortisol in women with a medical disorder during pregnancy. Arch Womens Ment Health 2010; 13(4): 339-345. DOI: https://doi.org/10.1007/s00737009-0139-5

11. Havnen GC, Truong MB-T, Do M-LH, et al. Women's perspectives on the management and consequences of hyperemesis gravidarum - a descriptive interview study. Scand J Prim Health Care 2019; 37(1): 30-40. DOI: https:// doi.org/10.1080/02813432.2019.1569424

12. Tan PC, Vani S, Lim BK, Omar SZ. Anxiety and depression in hyperemesis gravidarum: prevalence, risk factors and correlation with clinical severity. Eur J Obstet Gynecol Reprod Biol 2010; 149(2): 153-158. DOI: https://doi.org/10. 1016/j.ejogrb.2009.12.031

13. Nana M, Tydeman F, Bevan G, et al. Hyperemesis gravidarum is associated with increased rates of termination of pregnancy and suicidal ideation: results from a survey completed by $>5000$ participants. Am J Obstet Gynecol 2021; 224(6): 629-. DOI: https://doi.org/10.1016/j.ajog.2021.03.006

14. Fejzo MS, Magtira A, Schoenberg FP, et al. Antihistamines and other prognostic factors for adverse outcome in hyperemesis gravidarum. Eur J Obstet Gynecol Reprod Biol 2013; 170(1): 71-76. DOI: https://doi.org/10.1016/j. ejogrb.2013.04.017

15. Fejzo MS, Magtira A, Schoenberg FP, et al. Neurodevelopmental delay in children exposed in utero to hyperemesis gravidarum. Eur J Obstet Gynecol Reprod Biol 2015; 189: 79-84. DOI: https://doi.org/10.1016/j.ejogrb.2015.03. 028

16. Royal College of Obstetricians an Gynaecologists. The management of nausea and vomiting of pregnancy and hyperemesis gravidarum. 2016; https://www.rcog.org.uk/globalassets/documents/guidelines/green-top-guidelines/ gtg69-hyperemesis.pdf (accessed 25 Oct 2021).

17. Jarvis S, Nelson-Piercy C. Management of nausea and vomiting in pregnancy. BMJ 2011; 342: d3606. DOI: https:// doi.org/10.1136/bmj.d3606

18. Gadsby R, Barnie-Adshead T. Severe nausea and vomiting of pregnancy: should it be treated with appropriate pharmacotherapy? Obstet Gynaecol 2011; 13(2): 107-111. DOI: https://doi.org/10.1576/toag.13.2.107.27654

19. Pownall M. Time to change our attitudes to prescribing in pregnancy. Women's Health Medicine 2006; 3(5): 237-238. DOI: https://doi.org/10.1053/S1744-1870(06)70212-8

20. Matthews A, Dowswell T, Haas DM, et al. Interventions for nausea and vomiting in early pregnancy. Cochrane Database Syst Rev 2010(9): CD007575. DOI: https://doi.org/10.1002/14651858.CD007575.pub2

21. Dormuth $\mathrm{CR}$, Winquist $\mathrm{B}$, Fisher $\mathrm{A}$, et al. Comparison of pregnancy outcomes of patients treated with ondansetron vs alternative antiemetic medications in a multinational, population-based cohort. JAMA Netw Open 2021; 4(4): e215329): e215329: . DOI: https://doi.org/10.1001/jamanetworkopen.2021.5329

22. NICE. Nausea/vomiting in pregnancy. 2021; https://cks.nice.org.uk/topics/nausea-vomiting-in-pregnancy/ (accessed 25 Oct 2021).

23. Featherstone $\mathrm{Pl}$, James $\mathrm{C}$, Hall MS, Williams A. General practitioners' confidence in diagnosing and managing eye conditions: a survey in South Devon. Br J Gen Pract 1992; 42(354): 21-24.

24. Shah S, Harris M. A survey of general practitioner's confidence in their management of elderly patients. Aust Fam Physician 1997; 26: S12-17.

25. McCarthy FP, Murphy A, Khashan AS, et al. Day care compared with inpatient management of nausea and vomiting of pregnancy: a randomized controlled trial. Obstet Gynecol 2014; 124(4): 743-748. DOI: https://doi.org/ 10.1097/AOG.0000000000000449

26. Boelig RC, Barton SJ, Saccone G, et al. Interventions for treating hyperemesis gravidarum: a Cochrane systematic review and meta-analysis. J Matern Fetal Neonatal Med 2018; 31(18): 2492-2505. DOI: https://doi.org/10.1080/ 14767058.2017.1342805

27. Adams MM, Harlass FE, Sarno AP, et al. Antenatal hospitalization among enlisted servicewomen, 1987-1990. Obstet Gynecol 1994; 84(1): 35-39.

28. Gadsby R, Barnie-Adshead AM. Nausea and vomiting of pregnancy. 2011; https://www.pregnancysicknesssupport. org.uk/documents/NVP-lit-review.pdf (accessed 25 Oct 2021).

29. Fiaschi L, Nelson-Piercy C, Deb S, et al. Clinical management of nausea and vomiting in pregnancy and hyperemesis gravidarum across primary and secondary care: a population-based study. BJOG 2019; 126(10): 1201-1211. DOI: https://doi.org/10.1111/1471-0528.15662

30. McCarthy FP, Lutomski JE, Greene RA. Hyperemesis gravidarum: current perspectives. Int J Womens Health 2014; 6: 719-725. DOI: https://doi.org/10.2147/IJWH.S37685 
31. Campbell $\mathrm{K}$, Rowe $\mathrm{H}$, Azzam $\mathrm{H}$, Lane $\mathrm{CA}$. The management of nausea and vomiting of pregnancy. J Obstet Gynaecol Can 2016; 38(12): 1127-1137. DOI: https://doi.org/10.1016/j.jogc.2016.08.009

32. European Medicines Agency. PRAC recommendations on signals - adopted at the 8-11 July 2019 PRAC meeting. 2019; https://www.ema.europa.eu/en/documents/prac-recommendation/prac-recommendations-signals-adopted8-11-july-2019-prac-meeting_en.pdf (accessed 25 Oct 2021).

33. UKTIS. Official response statement. 2019; http://www.uktis.org/docs/Ondansetron\%20UKTIS\%20Response\% 20Statement.pdf (accessed 25 Oct 2021).

34. Mitchell-Jones N, Gallos I, Farren Jet al. Psychological morbidity associated with hyperemesis gravidarum: a systematic review and meta-analysis. BJOG 2017; 124(1): 20-30. DOI: https://doi.org/10.1111/1471-0528.14180

35. Dean CR, Shemar M, Ostrowski GAU, Painter RC. Management of severe pregnancy sickness and hyperemesis gravidarum. BMJ 2018; 363: k5000: k5000: . DOI: https://doi.org/10.1136/bmj.k5000 